\title{
Study of a pseudospark-sourced G-band EIO
}

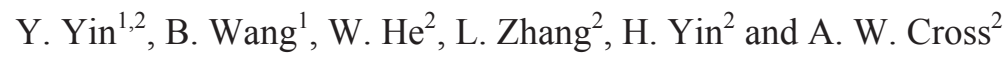 \\ ${ }^{1}$ University of Electronic Science and Technology of China, Chengdu, 610054, China \\ ${ }^{2}$ Department of Physics, SUPA, University of Strathclyde, Glasgow, Scotland, UK, G4 0NG
}

\begin{abstract}
Numerical study of a G-band Extended Interaction Oscillator (EIO) based on a pseudospark-sourced electron beam is presented. Preliminary results show a new way to generate several hundred watts of pulse power in millimeter and even terahertz frequency range in a compact and affordable way.
\end{abstract}

\section{INTRODUCTION}

$\mathrm{V}$ ACUMM electronic devices [1] above $100 \mathrm{GHz}$ are very attractive for a wide range of research and technical applications, including molecular spectroscopy, bio-imaging, security screening and communications. However, compact and affordable sources with an intermediate power level of hundreds watts are in demand for a number of important applications. The extended interaction devices such as the extended interaction klystron (EIK) and extended interaction oscillator (EIO) has been widely studied [2] as promising sources to satisfy this application as they combine the ruggedness and high power capability of a klystron and the wide bandwidth of a travelling wave tube. Operating the EIK/EIO above $100 \mathrm{GHz}$ requires small, high current density, precisely-aligned electron beams. Recent study on the pseudospark discharge demonstrated its potential in fulfilling the role. Electron beam pulses of thousands Amperes can be generated and transported in a $3 \mathrm{~mm}$ diameter tunnel without a guide magnetic field from the pseudospark discharges [3].

\section{PSEUdOSPARK-SOURCED G-BAND EIO}

Fig. 1 is the experimental layout of the pseudospark-sourced G-band EIO. $2 \pi$ mode was chosen as the operation mode of a nine-slot EIO circuit. The extended interaction circuit has a number of benefits, primarily raising the coupling impedance of the circuit enabling efficient modulation of the electron beam across a broad frequency band. Distributing the electric field across several gaps within a single cavity also has the benefit of reducing the electric field in the gaps, reducing the chances of breakdown and arcing. The high impedance of the extended interaction circuit reduces the total length of the interaction circuit, thus ensuring beam transmission.

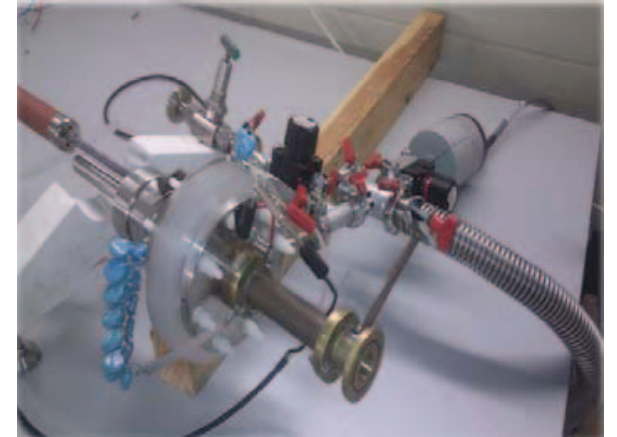

Fig. 1. Experiment layout of the pseudospark-sourced G-band EIO.

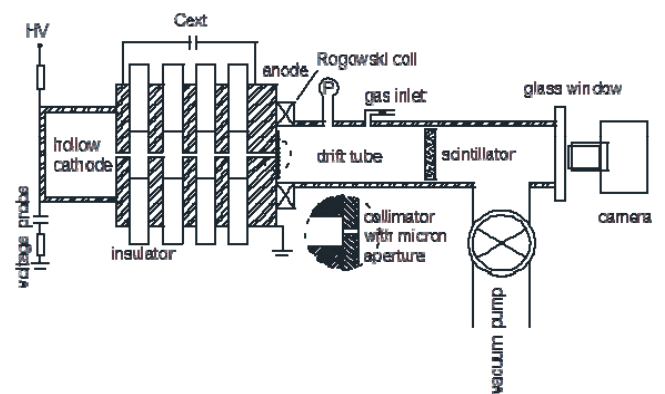

Fig. 2. A typical pseudospark-sourced electron beam experimental setup.

A typical four-gap pseudospark discharge setup is shown in Fig.2 [4]. The hollow cathode (pseudospark chamber) was connected to the DC power supply through a $30 \mathrm{M} \Omega$ charging resistor. The anode was grounded and there was no external applied guide magnetic field. Cext was the external capacitances. The electron beam was extracted from a four-gap pseudospark discharge chamber.

An electron beam with a time varying voltage as shown in Fig. 3 and with a constant current of $300 \mathrm{~mA}$ was injected into the interaction region. The resonant interaction of the electron beam with an oscillating electric field would cause the electron beam loss its energy to electromagnetic wave. The contour plot of Ez field in the interaction region is plotted in Fig. 4 when the oscillation in the circuit is established.

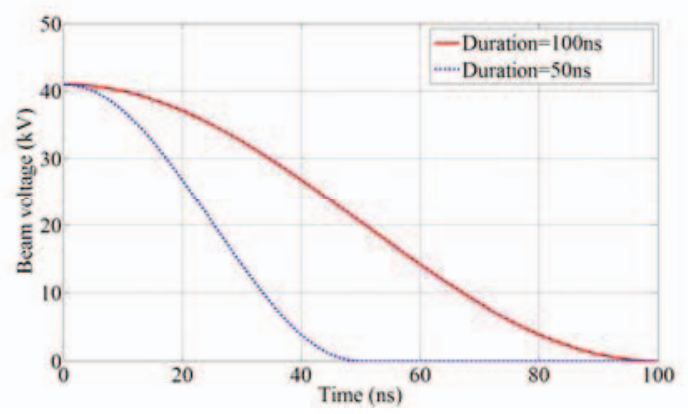

Fig. 3. The electron beam with time varied voltage.

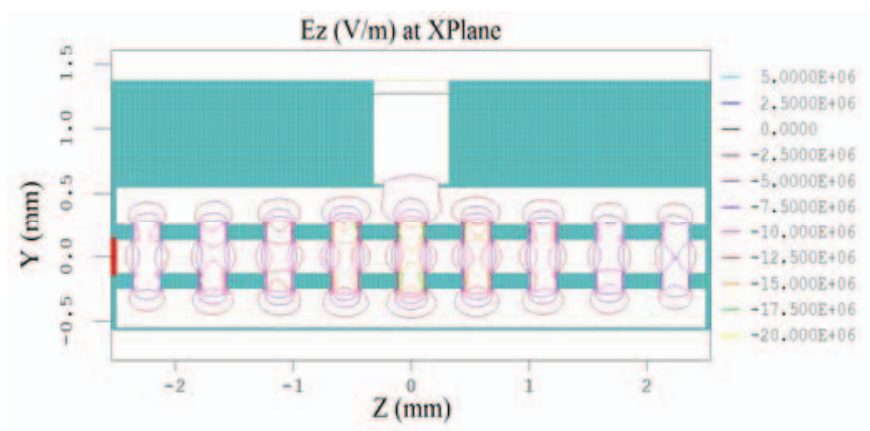

Fig. 4. A contour plot of the oscillating Ez field in the beam-wave interaction region. 
Fig. 5 is the simulation predicted output power with different time varying voltage. When the voltage of the pseudospark beam was changed from $41 \mathrm{kV}$ to $0 \mathrm{kV}$ in $50 \mathrm{~ns}$, an output power of $240 \mathrm{~W}$ at $189 \mathrm{GHz}$ with duration of $4-13$ ns was predicted from the simulation and is shown in Fig. 5 by the doted blue line. If the voltage reduces from $41 \mathrm{kV}$ to 0 in $100 \mathrm{~ns}$, and the other parameters are kept the same, an output power of $345 \mathrm{~W}$ with duration of 4-22 ns was predicted from the simulation as shown in Fig. 5 represented by the solid red line. The reason for the difference is the beam voltage duration because the EIO can only oscillate in a limited voltage region, hence the more time the beam voltage is in this region, the more output power can be obtained. As for the pseudospark-sourced electron beam, a lower rate of change in the beam voltage can ensure more electrons are located in the oscillating voltage region over a relatively longer time, thus improving the output power of the device. In pseudospark discharge, the discharging duration could be adjusted by applying different external capacitances.

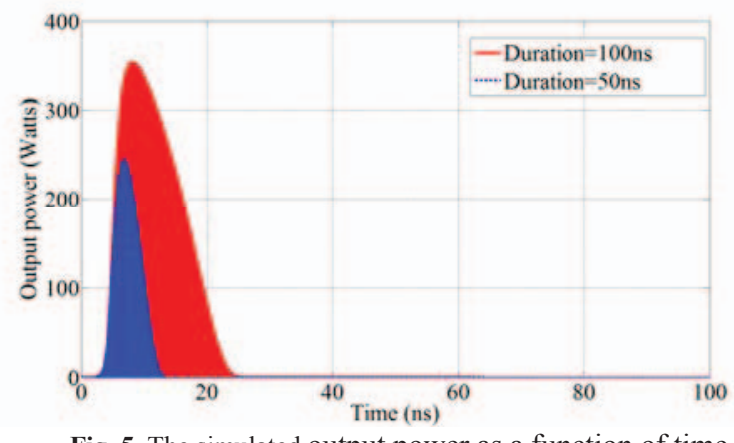

Fig. 5. The simulated output power as a function of time.

For the device itself, if the EIO circuit has a wide operation voltage region then the performance of the device will also be improved, especially when driven by a pseudospark-sourced electron beam.

\section{SUMMARY}

A pseudospark-sourced G-band EIO is proposed, which combines of the merit of the EIO and the pseudospark-sourced electron beam. Through optimize the charge capacitor, the output power of the EIO can be optimized to have several hundred watts. Our next step is to design and manufacture a G-band EIO circuit with a wide operating voltage region, and to utilize a large external capacitor in the pseudospark-sourced electron beam experimental setup to drive this circuit.

In summary a new way to generate several hundred watts of power in the millimeter and even terahertz frequency range from a pseudospark-sourced electron beam in a compact and affordable way has been demonstrated.

\section{ACKNOWLEDGMENTS}

This work was supported by the NSFC, China (Grant No. 61201011), the FRFCU, China (Grant No. ZYGX2013J056), and EPSRC, UK (research grant EP/G011087/1).

\section{REFERENCES}

[1]. J. H. Booske, R. J. Dobbs, C. D. Joye, C. L. Kory, G. R. Neil, G. S. Park, J. Park, R. J. Temkin, "Vacuum electronic high power terahertz sources," IEEE Trans. on Terahertz Science and Technology, vol. 1, pp. 54-75, Sep., 2011.

[2]. A. Roitman, D. Berry, B. Steer, "State-of-the-art W-band extended interaction klystron for the CloudSat program," IEEE Trans. On Electron Devices, vol. 51, pp. 895-898, May, 2005.

[3]. H. Yin , A. W. Cross, A. D. R. Phelps, D. Zhu , W. He, K. Ronald, "Propagation and post-acceleration of a pseudospark-sourced electron beam," Journal of Applied Physics, vol. 91, 5419, April, 2002.

[4]. H. Yin, A. W. Cross, W. He, A. D. R. Phelps, K. Ronald, D. Bowes, and C. W. Robertson, "Millimeter wave generation from a pseudospark-sourced electron beam," Physics of Plasmas, vol. 16, pp. 063105, June, 2009. 